\title{
Lifestyle among urology trainees and young urologist in the context of burn-out
}

syndrome.

Moisés Rodríguez-Socarrás ${ }^{1,2,3}$, Pernille Skjold Kingo ${ }^{1,4}$, Pieter Uvin ${ }^{1,5}$, Peter $\emptyset_{\text {stergren }}{ }^{1,6}$, Giulio Patruno ${ }^{1,7}$, Eric Edison ${ }^{8}$, Veeru Kasivisvanathan ${ }^{9}$,Juan L Vásquez ${ }^{1,6}$, Francesco

$$
\text { Esperto }^{1,10} \text {, Juan Gómez Rivas }{ }^{1,2,11} \text {. }
$$

1. European society of residents in Urology (ESRU).

2. European Association of Urology/Young Academics Urologists. Uro-Technology and communications working party (ESUT-YAU)

3. Department of Urology, Ospedale San Raffaele-Turro, Milan, Italy.

4. Department of Urology, Aarhus University Hospital, Aarhus, Denmark.

5. Department of Urology, University Hospitals Leuven, Leuven, Belgium.

6. Department of Urology. Copenhagen University Hospital Herlev. Copenhagen, Denmark.

7. Department of Urology, San Giovanni Hospital, Rome, Italy.

8. Department of Urology, Kingston Hospital, Galsworthy Road, Kingston upon Thames, Surrey, United Kingdom.

9. Division of Surgery and Interventional Science, University College London, London, UK; Department of Urology, University College London Hospitals NHS Foundation Trust, London, United Kingdom.

10. Department of Urology. Royal Hallamshire Hospital. Sheffield teaching hospital. United Kingdom.

11. Department of Urology, University Hospital La Paz, Madrid, Spain.

Running title: Lifestyle among urology residents and young urologist.

Words number: 2984

Corresponding author:

Juan Gómez Rivas. MD. PhD

Address: Paseo de la Castellana 261. La Paz University Hospital. Madrid-Spain. ZIP code 28046.

E-mail: juangomezr@gmail.com

Phone: +34 917277305 


\title{
Lifestyle among urology trainees and young urologist in the context of burn-out
} syndrome.

\begin{abstract}
:
Introduction: Burnout syndrome has increased dramatically in urology within recent years. A healthy lifestyle has been described as a protective factor. However, data on lifestyle is lacking among residents and urologists and remains to be elucidated. We aim to assess lifestyle among urology residents and young urologists across Europe.
\end{abstract}

Materials and methods: Members of the European Society of Residents in Urology (ESRU) designed a 34-item online survey via surveymonkey.com. The survey was designed in accordance with Checklist for Reporting Results of Internet E-Surveys (CHERRIES) guidelines and was distributed via e-mail and social media in 23 European countries to urology residents and young urologists. The primary endpoint was reported as self-perceived health status. Secondary endpoints included questions on sleeping disorders, exercise and dietary habits. Data was analyzed SPSS software.

Results: A total of 412 residents and young urologists responded to the survey. The mean age of the respondents was $31.4 \pm 3.9 \mathrm{yr}$. The data on dietary intake demonstrate a mean of 2 or more cups/day of coffee and alcohol consumption 2-3 times/week. The intake of fruits and vegetables is very low, almost $60 \%$ of responders consume $<1$ portions of fruit/day and more than half $(52 \%)$ eat $<1$ portion of vegetable/day. Overall, the majority of respondents reported to have a moderate to low satisfaction with lifestyle (59.65\%) and low to moderate self-perceived health status (45.94\%). Moreover, $46 \%$ of respondents reported to have some kind of sleep disturbance and $60 \%$ only slept 6 hours/night or less with $53 \%$ reporting a moderate to 
very low quality of Sleep. Regular exercise of at least 30 min twice weekly was only performed by $33 \%$ of the respondents.

Conclusions: Residents and young urologists have unbalanced diet, tend to exercise too little and often suffer from sleep disturbances all of which increases the risk of burnout. Physicians, organizations and institutions should strive to promote healthy lifestyle, resiliency and support programs.

Keywords: burnout syndrome, lifestyle, urology, training, resiliency, sleep disturbances 


\section{INTRODUCTION}

Depression, stress and burnout syndrome have become a genuine problem in the urology specialty. Burnout seems to have become a mass phenomenon, receiving constant media attention. More and more people are missing work due to burnout. The term "burnout" was coined in the 1970 s by the American psychologist Herbert Freudenberger. He used it to describe the consequences of severe stress and high ideals in "helping" professions. Doctors and nurses, for example, who sacrifice themselves for others, would often end up being "burned out": exhausted, listless, and unable to cope. Nowadays, the term has entered the common vernacular from stressed-out careerists and celebrities to overworked employees and homemakers. (1)

Surprisingly, there is no clear definition of what burnout really is. Most comon defnition used is that burnout syndrome is a state of emotional, mental, and physical exhaustion caused by excessive and prolonged stress. It occurs when you feel overwhelmed and unable to meet constant demands. As the stress continues, you begin to lose the interest or motivation that led you to take on a certain role in the first place. Various figures appear in the press; some German health insurance companies say that up to nine million people are affected in Germany. $(1,2)$

Burnout syndrome frequency is higher among health professionals than in the general population and its incidence has increased rapidly in recent years (2-6). Urology is one of the specialties with the highest incidence and severity of burnout (7). This increase in recent years might be partly explained by an increase in the proportion of time health professionals spend on bureaucracy compared to having patient contact and performing surgery. (8-10) 
The prevalence of burnout syndrome among medical students and residents have been reported to be around $40-76 \%(5,8)$. Factors related include: work overload, documentation, administrative / bureaucratic workloads, a hostile work environment, experience with suffering, adaptability, stressful life events, gender, marital status, academic activity and lifestyle. (12-14)

Burnout can lead to poor work performance, medical errors, depression, substance abuse, family and relationships disruption and suicidal ideation. Data from American Foundation for Suicide Prevention shows an estimated $300-400$ physicians death due to suicide in the U.S. per year. (15-18)

Prevention strategies of burnout syndrome include resilience training, a balanced lifestyle, teamwork, and support programs. Healthy lifestyle is a key protective factor against stress and leads to greater work performance and patient satisfaction. (19-21)

With this study we aimed to assess self-perceived health status, sleep disturbances and lifestyle habits among urology residents and young urologists from European countries in order to shed some light on this neglected important issue.

\section{MATERIAL AND METHODS}

Members of the European Society of Residents in Urology (ESRU) designed a 34-item online survey using the platform www.surveymonkey.com (SurveyMonkey, Portland, OR, USA). The survey was designed and carried out in accordance with the Checklist for Reporting Results of Internet E-Surveys (CHERRIES). (22) 
Demographic data of respondents included: age, gender, current work status (resident/urologist) and country. Variables related to lifestyle included: self-perceived health status (SPHS), overall satisfaction with lifestyle (SL) hours of sleep, sleep disturbances, Quality of Sleep (QoS). Fruit and vegetable intake, coffee and alcohol consumption, smoking habit, weekly performed exercise, (Appendix/Supplementary data 1 include complete Survey). Initially the survey was tested to verify its correct usability and technical functionality, and then it was sent via mailing list of ESRU to the national communicator officers (NCOs). In addition, we disseminated the survey using social media (SoMe) accounts of the European Society of Residents in Urology. Data was collected from January 2017 to January 2018.

\section{Statistical Analysis}

Statistical Package for the Social Sciences (SPSS) software version 21.0 (SPSS Inc., Chicago, IL, USA) was used for descriptive statistics and statistical analysis. Variables are expressed as means \pm standard deviation (SD). Subset analyses were performed comparing lifestyle variables between groups according to different demographic characteristics. In the comparative analysis, lifestyle were stratified by training status (residents vs certified urologists), gender (male vs female), age (younger than mean age vs older than or equal to mean age) and marital status (single, married, divorced). Statistical significance was accepted at $p$-values $<0.05$

\section{RESULTS:}

A total of 412 residents and young urologist responded to the survey. The mean age of the respondents was $31.4 \pm 3.9 \mathrm{yr}$. The majority of responders were from Spain, 
Belgium, Denmark and Italy, representing more than a half $(51 \%)$ of the polled population. Demographic data for the survey respondents are shown in Table 1.

\section{Dietary Habits}

The dietary habits (Table 2 ) revealed a coffee intake of 2-4 cups/day (55\% respondents). With regards to alcohol consumption, $29.9 \%$ of the respondents reported to drink alcohol 2-3 times/month (especially on weekends), 2-3 times/week by $27.7 \%$ and daily by $5.6 \%$. Moreover, $22.6 \%$ of responders were smokers or former smokers. The intake of fruit and vegetables showed that $60 \%$ of responders consume $\leq 1$ portions of fruit/day and around half (52\%) eat $\leq 1$ portion of vegetable/day.

Exercise, sports and sleep characteristics.

The large majority (77\%) do not perform exercise, or perform $<2$ times/week physical exercise ( $\geq 30$ minutes) (Table 2 ).

Sleep characteristics showed that $60 \%$ of responders reported 6 hours of sleep/night or less; almost half of responders have some sleep problem (46\%) as difficulty initiating sleep, interrupted sleep or early awakenings. Furthermore, 53\% reported a moderate to very low Quality of Sleep (Table 2 \& Figure 1).

Lifestyle and Health status

Satisfaction with Lifestyle (SL) rates were perceived as moderate to low by $59.65 \%$ and self-perceived health status (SPHS) as moderate to low by $45.94 \%$ of respondents (Figure 2). Additionally, 35\% admitted that their health status interferes with their daily activity at home and treating patients (Figure 3-5). 


\section{DISCUSSION}

This is the first survey to report on lifestyle among residents and young urologists across Europe. Satisfaction with Lifestyle (SL) rates were perceived as moderate to low by $59.65 \%$ and self-perceived health status (SPHS) perceived as moderate to low by $45.94 \%$ of respondents.

Spain, Italy, Denmark and Belgium represent half of the respondents (51\%). This could be explained by several factors 1 ) according to the ESRU database, these countries are in the top 10 in number of residents and together they represent more than half of residents (> 2200 of 3300 residents), 2) in accordance with previous surveys there is a good response rate in these countries, reflecting a good line of communication of ESRU through email list and adoption of SoMe 3) there is great interest in issues affecting residents and young urologists, 4) burnout syndrome, depression and lifestyle are topics currently of great interest in the urological community. This interest is also reflected by the fact that this survey has reached the highest number of respondents of all surveys carried out from ESRU (412 respondents). (23)

Burnout syndrome is characterized by 1) emotional exhaustion (EE), 2) depersonalization (DP) and 3) low personal performance (PA) or feeling of low achievement $(1,2)$. According to the "Lifestyle report: Race and ethnicity, bias and burnout syndrome 2017" published in Medscape, a considerable increase has been observed in the years 2013 - 2017. More than 14.000 doctors from 30 specialties showed surprising results. The overall frequency of burnout syndrome was $41 \%$ and in 2017 it was 51\%. It is striking that among the specialists who reported burnout syndrome, urologists had the highest severity score (average severity score: 4.6) (11). 
The evidence from the few studies carried out so far highlights the importance that attention should be given to this topic in our specialty. In order to prevent burnout syndrome and the consequences of this, appropriate studies should be carried out to develop strategies on how to inform and advise urologists and residents.

Regarding urology, O'Kelly F et al, developed in 2015 a survey among members of the Irish Urological Society (ISU) and the British Urological Society (BAUS). The survey reached 575 respondents (response rate of 42\%). They reported a mean EE of $23.5 \%$ (considered moderate), an average of DP of $82 \%$ (considered moderate) and a PA of 17.1\%. Furthermore they revealed that $80 \%$ (460 respondents) agree that burnout syndrome should be evaluated among professionals of Urology and in addition $60 \%$ (345 respondents) would like to receive advice if they were offered (12). These results are worrying and should be taken seriously.

According to several studies of residents and specialists surveyed in several surgical specialties, greater differences were found in burnout when comparing both groups. Based on $\mathrm{MBI}$ scores (Maslach burn-out syndrome Inventory) residents during the specialty are more likely to experience burnout syndrome and depression than specialists. In addition, residents asked in several studies reported less QoL satisfaction than specialists. $(6,8,24)$

Burnout syndrome has been related to work overload, documentation, administrative/bureaucratic workload, hostile work environment; its consequences include poor work performance, medical errors, depression, substance abuse, disruption in family, couple relationships and suicidal ideation. (15-18) 
Studies suggest that burnout syndrome and depression impact on QoL and lifestyle, and that, conversely, a healthy lifestyle is a protective factor $(17,19-21)$. However, lifestyle factors among urologists and residents of urology have not been studied previously. According to the results of this survey, young residents and urologists do not seem to lead a healthy lifestyle, many consume $<1$ portion of vegetables or fruit per day. The vast majority (77\%) does not perform exercise or perform less than 2 times/week physical exercise of more than 30min duration. The observed unhealthy lifestyle could have a role in burnout and depression in young and resident urologists. Furthermore, we must remember that healthy lifestyle and well-being in doctors is also related to a better quality of care and advice to patients. Consequently the unhealthy lifestyle observed among young urologists and residents may have negative consequences in the care of patients and advice in urological diseases.

Alterations of sleep patterns is one of the most frequently findings in professionals who exhibit burnout syndrome $(2-4,7)$ On this survey, almost half of responders have sleep problems (46\%) as difficulty initiating sleep, interrupted sleep or early awakenings. In addition, they claimed to sleep $\leq 6$ hours (60\%), with quality of sleep rated as moderate to low (52\%), but despite this almost all report not using sleeping pills (96\%).

In this survey, we included three questions from validated questionnaires (Figures 3-5), almost a third of the respondents admitted that they have fallen asleep in situations like "in front of the computer or when traffic is arrested", that "physical health interferes with daily activity in the home" and also with "ability to treat patients" $(3,4,8)$. These responses reflect the state of exhaustion of urology residents and young 
urologists, which can have serious implications in the treatment of patients, the ability to make decisions and might lead to medical errors. Previous studies have estimated that $15-30 \%$ of medical errors may be due to exhaustion of health professionals. (18)

Academic studies of burnout syndrome have specifically identified factors related to to it, including work overload, documentation, administrative / bureaucratic workload, academic activity, hostile work environment and experience with suffering. In contrast, others factors have been described as protective such as resilience, adaptability to stressful life events, marriage, familiar support, healthy lifestyle, regular physical activity, annual visits to primary care physicians, and a variety of other personal wellness strategies, including focusing on what It is personally important in life, taking vacations and nurture the religious / spiritual aspects (25-29). Factors like gender are controversial to be related to burnout syndrome (3-5). According to our survey data, $39 \%$ of respondents are married and another $22 \%$ are in a relationship. In addition $67 \%$ are men and $33 \%$ women, one would say that urology has been a predominantly male specialty for years, fortunately the number of female specialists is growing in recent years; although the studies do not clearly indicate a link between burnout syndrome and gender, future studies are needed to find out if gender can play a role.

It is necessary to take strategies to fix this problem. Strategies for prevention include resilience training, lifestyle balance, teamwork, and support programs. Many authors and academic studies agree that the most important individual strategy to promote is resilience. Resilience refers to the ability of an individual to adapt to adversity. Resilience correlates positively with low psychosocial stress and high well-being. Prospective studies suggest that resilience training can improve psychological 
disorders, self-efficacy and self-esteem Although resilience programs can take a considerable amount of time, it has been shown that a brief intervention among physicians has the potential to improve stress, anxiety and quality of life. (26-29)

Another concept that should be considered is leadership, in this sense members of the Young Urologists Office (EAU-YUO), have launched leadership training programs. The understanding of the concept of leadership encompasses a different point of view and a paradigm shift to the traditional boss model in force. The importance of this topic is that a leader should represent the cornerstone on which a urology service is based.

Recognizing the dangers of an exhausted doctor with burnout syndrome, some health care organizations have instituted programs designed to promote resilience and wellbeing among their staff, like the SWADDLE program (Staff Well-being Assistance During Difficult Life Events) from Baylor Scott \& White Health, the health system in Texas, also the LiveWell program (Work, Eat, Learn, and Live) of the Carolina health system and the WellMD of the Stanford health system. These programs offer resilience techniques, stress management, healthy behaviors to doctors, free courses, expert talks and a variety of online resources including webinars, as well as personalized support during stress situations and crisis. (31-32)

The present study has some limitations. Although it represents the largest lifestyle survey in urology and has reached the highest number of responders of surveys from ESRU (with more than 400 respondents), the population of the survey might not be a true representation of the urological population because it has been distributed via email list and SoMe. In addition, people who identify with this issue may be more likely 
to answer the survey, while those who are not interested may ignore it. Here, it was not possible to determine the defined number of recipients, which is a common phenomenon on research using online surveys distributed via SoMe. Therefore, we could not calculate a response rate. In addition, there are no validated questionnaires regarding lifestyle in urologists. However, we designed and distributed the survey in accordance with CHERRIES guidelines to achieve the best possible methodological quality. Moreover, the nature of the survey provides subjective responses that reflect the respondents' judgments rather than an objective evaluation.

Finally, while it is true that there are no support programs in exhaustion and burnout for doctors in several countries in Europe, it is our duty to make a call for reflection through this study to the problems of both lifestyle and burnout among doctors, residents and urologists. One of the issues is probably an existing gap in the support from the system, it is important to promote strategies in resilience and healthy lifestyle, in fact there are a variety of online resources in SoMe platforms such as YouTube, in resilience, coaching and positive psychology that are available to everyone.

\section{CONCLUSION}

Residents and young urologists have unbalanced diet, tend to exercise too little and a fairly amount suffer from sleep disturbances all of which may increases the risk of burnout syndrome. They report that their lifestyle impacts on their personal life as well as their delivery of patient care. Healthcare organizations should strive to promote healthy lifestyle, resiliency and supports programs. 


\section{COMPLIANCE WITH ETHICAL STANDARDS}

Authors declare that there are no conflicts of interest, this research does not include human participants and/or animals, so no informed consent in needed.

\section{REFERENCES}

1. Korczak D, Kister C, Huber B. Differential diagnostik des Burnout-Syndroms. HTABericht 105. Deutsches Institut für Medizinische Dokumentation und Information (DIMDI). Cologne; 2010.

2. Rodríguez-Socarrás M, Vasquez JL, Uvin P, Skjold-Kingo P, Gómez Rivas J. Fatigue syndrome: Stress, Burnout and depression in Urology. Arch Esp Urol. 2018 Jan;71(1):46-54.

3. Mata DA, Ramos MA, Bansal N, Khan R, Guille C, Di Angelantonio E, et al. Prevalence of Depression and Depressive Symptoms Among Resident Physicians: A Systematic Review and Meta-analysis. JAMA. 2015 Dec 8;314(22):2373-83.

4. Shanafelt TD, Hasan O, Dyrbye LN, Sinsky C, Satele D, Sloan J, et al. Changes in burnout syndrome and satisfaction with work-life balance in physicians and the general US working population between 2011 and 2014. Mayo Clin Proc. 2015 Dec;90(12):1600-13.

5. Balch CM, Shanafelt TD, Sloan JA, Satele DV, Feischlag JA. Distress and career satisfaction among 14 surgical specialities, comparing academic and private practice settings. Ann Surg 2011;254:558-68.

6. Shanafelt TD, Boone S, Tan L, Dyrbye LN, Sotile W, Satele D, et al. Burnout and satisfaction with work-life balance among US physicians relative to the general US population. Arch Intern Med. 2012 Oct 8;172(18):1377-85. 
7. Franc-Guimond J, McNeil B, Schlossberg SM, North AC, Sener A. Urologist burnout: Frequency, causes, and potential solutions to an unspoken entity. Canadian Urological Association Journal. 2018;12(4):137-142.

8. Dyrbye LN, West CP, Satele D, Boone S, Tan L, Sloan J, et al. Burnout syndrome among U.S. medical students, residents, and early career physicians relative to the general U.S. population. Acad Med. 2014 Mar;89(3):443-51.

9. Babbott S, Manwell LB, Brown R, Montague E, Williams E, Schwartz M. et al. Electronic medical records and physician stress in primary care: results from the MEMO Study. J Am Med Inform Assoc. 2014 Feb;21(e1):e100-6.

10. Pulcrano M, Evans SR, Sosin M. Quality of Life and burnout syndrome Rates Across Surgical Specialties: A Systematic Review. JAMA Surg. 2016 Oct 1;151 (10):970-978.

11. Peckham C. Medscape Lifestyle Report 2017: Race and Ethnicity, Bias and burnout. Janaury, $2017 . \quad$ Retrieved from: http://www.medscape.com/features/slideshow/lifestyle/2017/overview. Accessed August $8^{\text {th }}, 2018$

12. O'Kelly F, Manecksha RP, Quinlan DM, Reid A, Joyce A, O'Flynn K, et al. Rates of self-reported 'burn-out syndrome' and causative factors amongst urologists in Ireland and the UK: a comparative cross-sectional study. BJU Int. 2016 Feb; $117(2): 363-72$.

13. Balch CM, Shanafelt TD, Dyrbye L, Sloan JA, Russell TR, Bechamps GJ, et al. Surgeon distress as calibrated by hours worked and nights on call. J Am Coll Surg. 2010 Nov;211(5):609-19.

14. Rodríguez-Socarrás ME, Gómez Rivas J, García-Sanz M, Pesquera L, TortoleroBlanco L, Ciappara $M$ et all. Medical-surgical activity and the current state of 
training of urology residents in Spain: Results of a national survey. Actas Urol Esp. 2017 Jul - Aug;41(6):391-399.

15. Shanafelt TD, Balch CM, Dyrbye L, Bechamps G, Russell T, Satele D, et al. Special report: suicidal ideation among American surgeons. Arch Surg. 2011 Jan;146(1):5462.

16. American Foundation for Suicide Prevention (2016), "Physician and medical student depression and suicide prevention". Retrieved from: https://afsp.org/ourwork/education/physician-medical-student-depression-suicide-prevention/ Accessed July $2^{\text {th }}, 2018$.

17. Dyrbye L, Shanafelt T, Timbros J. Protecting and Promoting the Well-being of Surgeons: Basics of Surgery. Maarssen, Germany: Elsevier Gezondheidzorg; 2007:177-184.

18. Shanafelt TD, Balch CM, Bechamps G, Russell T, Dyrbye L, Satele D, et al. Burnout and medical errors among American surgeons. Ann Surg. 2010 Jun;251(6):9951000.

19. Shanafelt, T.D., Kaups, K., Nelson, H., Satele, D., Sloan, J., Oreskovich, et al. An interactive individualized intervention to promote behavioral change to increase personal well-being in US surgeons, Annals of Surgery, Vol. 259 No. 1, pp. 82-88.

20. Dissanaike S. How to prevent burnout syndrome. Am J Surg 2016;212:1251-5.

21. Squiers JJ, Lobdell KW, Fann JI, DiMaio JM. Physician burnout: Are We Treating the Symptoms Instead of the Disease?. Ann Thorac Surg. 2017 Oct;104(4):1117-1122.

22. Eysenbach G. Improving the quality of web surveys: The checklist for reporting results of internet e-surveys (CHERRIES). J Med Internet Res 2004;6:e34. 
23. Rivas JG, Socarras MR, Patruno G, Uvin P, Esperto F, Dinis PJ, Roupret M, Borgmann H. Perceived Role of Social Media in Urologic Knowledge Acquisition Among Young Urologists: A European Survey. Eur Urol Focus. 2017 Jul 27. pii: S24054569(16)30168-7.

24. Shanafelt TD, Bradley KA,Wipf JE, Back AL. Burnout syndrome and self-reported patient care in an internal medicine residency program. Ann Intern Med. 2002;136(5):358-367.

25. Maslach C, Jackson S, Leiter M. Maslach Burnout syndrome Inventory Manual. 3rd ed. Palo Alto, CA: Consulting Psychologists Press; 1996.

26. Harker R, Pidgeon AM, Klaassen F, King S. Exploring resilience and mindfulness as preventative factors for psychological distress, burnout and secondary traumatic stress among human service professionals. Work. 2016 Jun 8;54(3):631-7.

27. Babyar JC. They did not start the fire: reviewing and resolving the issue of physician stress and burnout. J Health Organ Manag. 2017 Jun 19;31(4):410-417.

28. Dyrbye LN, Trockel M, Frank E, et al. Development of a research agenda to identify evidence-based strategies to improve physician wellness and reduce burnout. Arch Intern Med 2017;166:743-4.

29. Sood A, Sharma V, Schroeder DR, Gorman B. Stress Management and Resiliency Training (SMART) program among Department of Radiology faculty: a pilot randomized clinical trial. Explore (NY). 2014 Nov-Dec;10(6):358-63.

30. Leadership for Medical Professionals Course from The EAU Young Urologists Office (YUO). Retrieved from: http://eau18.uroweb.org/improve-your-managementwith-a-special-leadership-for-medical-professionals-course/. Accessed August $10^{\text {th }}$, 2018. 
31. Magtibay DL, Chesak SS, Coughlin K, Sood A. Decreasing Stress and burnout syndrome in Nurses: Efficacy of Blended Learning With Stress Management and Resilience Training Program. J Nurs Adm. 2017 Jul/Aug;47(7-8):391-395.

32. Schulte B. Time in the bank: a Stanford plan to save doctors from burnout. The Washington Post Aug 20, 2015. Retrieved from: https://www.washingtonpost.com/news/inspired-life/wp/2015/08/20/theinnovative-stanford-program-thats-savingemergency-room-doctors-fromburnout/?utm_term1/4.889aa2f4f01f. Accessed August 12 ${ }^{\text {th }}, 2018$.

\section{FIGURE LEGENDS}

Figure 1. Sleeping problems. Lifestyle survey among residents and young urologist in Europe.

Figure 2. Self-perceived health status (A) and satisfaction with lifestyle (B). Lifestyle survey among residents and young urologist in Europe.

\section{SUPPLEMENTARY DATA}

Appendix/Supplementary data 1. Lifestyle survey among residents and young urologist in Europe. Full questionnaire.

Appendix/Supplementary data. Figure 3. Survey question. Have you recently fallen asleep when you where in a situation such as: traffic stopped, driving, at the computer, on the subway or bus?

Appendix/Supplementary data. Figure 4. Survey question. Has your physical health interfered with your ability to do your daily work at home?

Appendix/Supplementary data. Figure 5. Survey question. Has your physical health/stress interfered with your ability treating patients? 


\begin{tabular}{|c|c|}
\hline Age & $31.4 \pm 3.9 \mathrm{yr}$ \\
\hline \multirow[t]{2}{*}{ Gender } & Male: $67.2 \%$ \\
\hline & Female: 32.8\% \\
\hline \multirow[t]{3}{*}{ Current status } & Resident: $76.4 \%$ \\
\hline & Urologist: $22.4 \%$ \\
\hline & Other: $1.2 \%$ \\
\hline \multirow[t]{4}{*}{ Marital Status } & Single $36.9 \%$ \\
\hline & Married $39.8 \%$ \\
\hline & Divorced $1.2 \%$ \\
\hline & In a Relationship (unmarried) $22.1 \%$ \\
\hline \multirow[t]{18}{*}{ Country } & Austria $0.5 \%$ \\
\hline & Belgium 9.5\% \\
\hline & Denmark $12.1 \%$ \\
\hline & France $10.0 \%$ \\
\hline & Grece $0.2 \%$ \\
\hline & Georgia $1.0 \%$ \\
\hline & Germany $1.2 \%$ \\
\hline & Hungary $8.0 \%$ \\
\hline & Ireland $0.7 \%$ \\
\hline & Italy $11.9 \%$ \\
\hline & Lithuania $0.5 \%$ \\
\hline & Netherlands $1.0 \%$ \\
\hline & Poland $0.7 \%$ \\
\hline & Portugal 3.9\% \\
\hline & Slovakia 3.9\% \\
\hline & Slovenia $1.5 \%$ \\
\hline & Spain $18.4 \%$ \\
\hline & Sweden $0.5 \%$ \\
\hline
\end{tabular}




\begin{tabular}{|l|l|}
\hline & Switzerland 0.5\% \\
\hline & Turkey $4.9 \%$ \\
\hline & UK $1.9 \%$ \\
\hline & Others: $7.2 \%$ \\
\hline
\end{tabular}

Table 1. Demographics of $\mathbf{4 1 2}$ respondents to Lifestyle survey among urology residents and young urologist in Europe. 


\begin{tabular}{|c|c|c|c|}
\hline Item & Amount & Respondents & $\%$ \\
\hline \multirow[t]{6}{*}{ Coffee /Day } & 0 & 69 & $16.7 \%$ \\
\hline & 1 & 84 & $20.4 \%$ \\
\hline & 2 & 101 & $24.5 \%$ \\
\hline & 3 & 80 & $19.4 \%$ \\
\hline & 4 & 49 & $11.9 \%$ \\
\hline & 5 & 29 & $7 \%$ \\
\hline \multirow[t]{5}{*}{ Alcohol } & Never & 56 & $13.6 \%$ \\
\hline & Weekends & 123 & $29.9 \%$ \\
\hline & 2-3 / month & 96 & $23.3 \%$ \\
\hline & 2-3/week & 114 & $27.7 \%$ \\
\hline & Daily & 23 & $5.6 \%$ \\
\hline \multirow[t]{3}{*}{ Smoking habit } & Never & 319 & $77.4 \%$ \\
\hline & Smoker & 63 & $15.3 \%$ \\
\hline & Former Smoker & 30 & $7.3 \%$ \\
\hline \multirow[t]{6}{*}{ Energy Drinks/week } & 0 & 355 & $86.2 \%$ \\
\hline & 1 & 25 & $6.1 \%$ \\
\hline & 2 & 11 & $2.7 \%$ \\
\hline & 3 & 10 & $2.4 \%$ \\
\hline & 4 & 5 & $1.2 \%$ \\
\hline & 5 & 6 & $1.5 \%$ \\
\hline \multirow[t]{6}{*}{ Junk Food/Week } & 0 & 100 & $25.4 \%$ \\
\hline & 1 & 182 & $46.2 \%$ \\
\hline & 2 & 52 & $13.2 \%$ \\
\hline & 3 & 31 & $7.9 \%$ \\
\hline & 4 & 13 & $3.3 \%$ \\
\hline & 5 & 16 & $4.1 \%$ \\
\hline Fruits / Day & 0 & 41 & $10.4 \%$ \\
\hline
\end{tabular}




\begin{tabular}{|c|c|c|c|}
\hline & 1 & 194 & $49.2 \%$ \\
\hline & 2 & 97 & $24.6 \%$ \\
\hline & 3 & 43 & $10.9 \%$ \\
\hline & 4 & 11 & $2.8 \%$ \\
\hline & 5 & 8 & $2.0 \%$ \\
\hline \multirow[t]{5}{*}{ Vegetables/Day } & 0 & 44 & $10.6 \%$ \\
\hline & 1 & 174 & $42.2 \%$ \\
\hline & 2 & 130 & $31.6 \%$ \\
\hline & 3 & 50 & $12.2 \%$ \\
\hline & 4 & 14 & $3.4 \%$ \\
\hline \multirow[t]{4}{*}{ Exercise $>30 \mathrm{~min} /$ week } & 0 & 117 & $28.43 \%$ \\
\hline & $1-2$ & 204 & $49.49 \%$ \\
\hline & $3-5$ & 74 & $18.02 \%$ \\
\hline & $>5$ & 17 & $4.06 \%$ \\
\hline \multirow{8}{*}{$\begin{array}{l}\text { Exercise/Sport } \\
\text { performed }\end{array}$} & Fitness & 110 & $26.65 \%$ \\
\hline & Running & 157 & $38.07 \%$ \\
\hline & Swimming & 53 & $12.94 \%$ \\
\hline & Biking & 92 & $22.34 \%$ \\
\hline & Tennis & 21 & $5.08 \%$ \\
\hline & $\begin{array}{l}\text { Group sports (Soccer, } \\
\text { Basketball, Rugby, } \\
\text { Handball..) }\end{array}$ & 61 & $14.72 \%$ \\
\hline & Other & 58 & $14.21 \%$ \\
\hline & None & 89 & $21.57 \%$ \\
\hline \multirow[t]{4}{*}{ Sleep Hours } & $<4$ & 6 & $1.52 \%$ \\
\hline & 5 & 66 & $15.99 \%$ \\
\hline & 6 & 179 & $43.40 \%$ \\
\hline & 7 & 156 & $37.82 \%$ \\
\hline
\end{tabular}




\begin{tabular}{|l|l|l|l|}
\hline & $>8$ & 5 & $1.27 \%$ \\
\hline Quality of Sleep & Very High & 34 & $8.38 \%$ \\
\hline & High & 157 & $38.32 \%$ \\
\hline & Moderate & 181 & $43.65 \%$ \\
\hline & Low & 36 & $8.63 \%$ \\
\hline & Very Low & 4 & $1.02 \%$ \\
\hline
\end{tabular}

Table 2. Lifestyle variables of the $\mathbf{4 1 2}$ respondents survey among Residents and young urologist in Europe. 


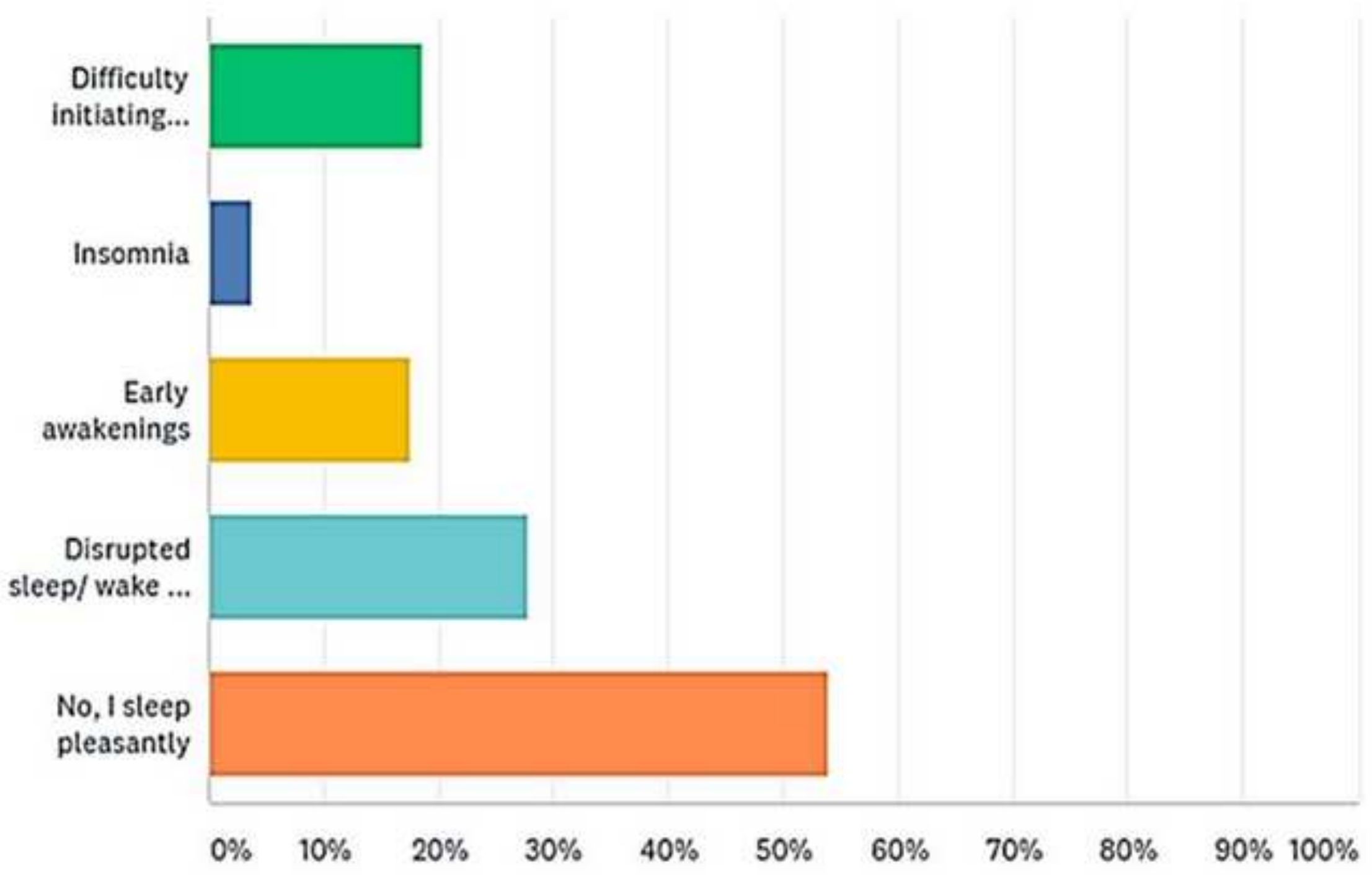


Figura (Figure) 2

Click here to download high resolution image
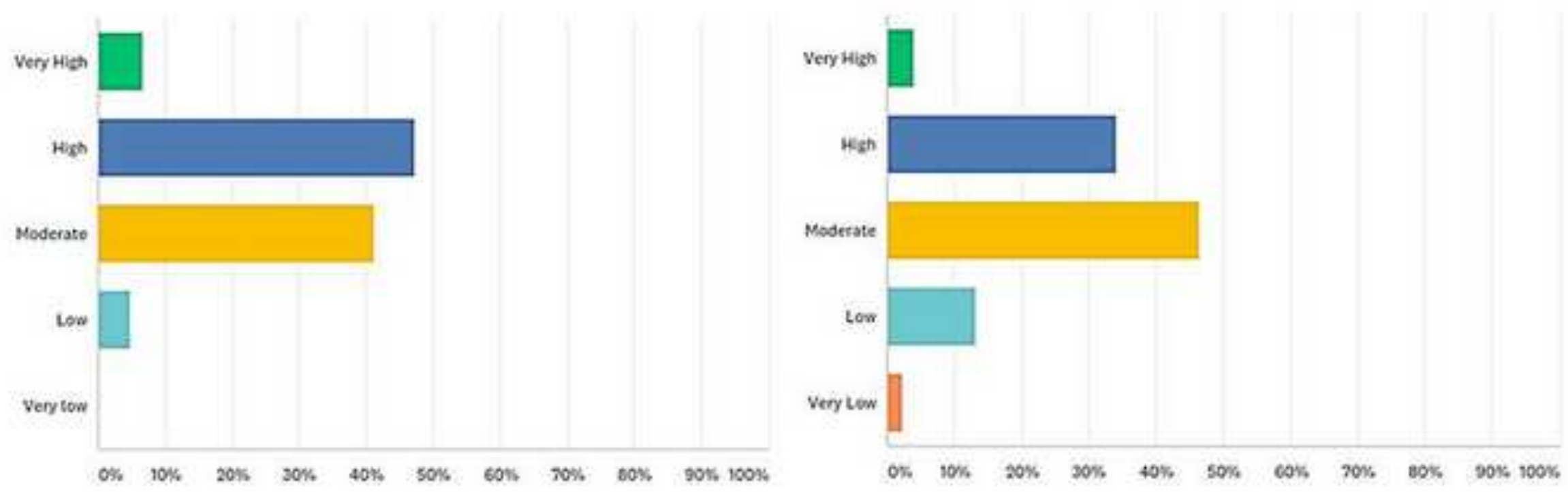

A 
Figura (Figure) 3

Click here to download high resolution image

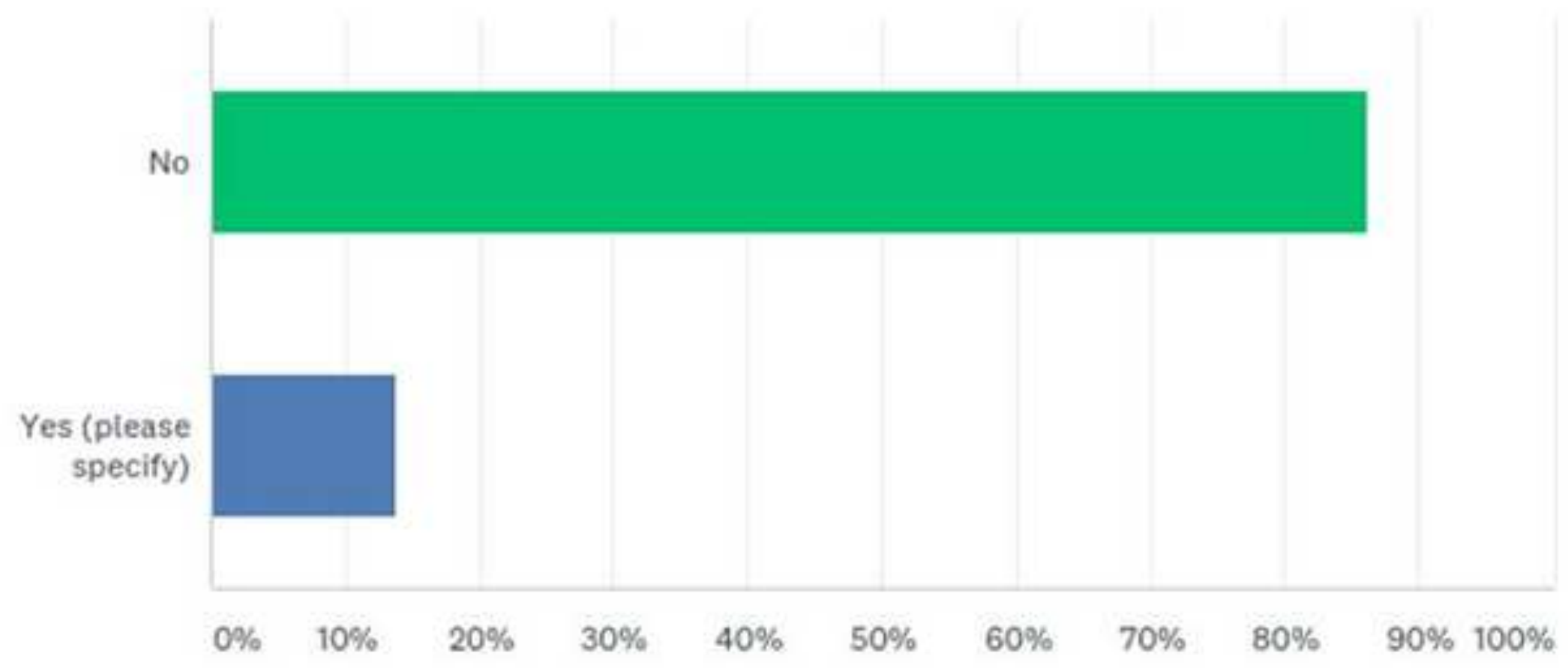


Figura (Figure) 4

Click here to download high resolution image

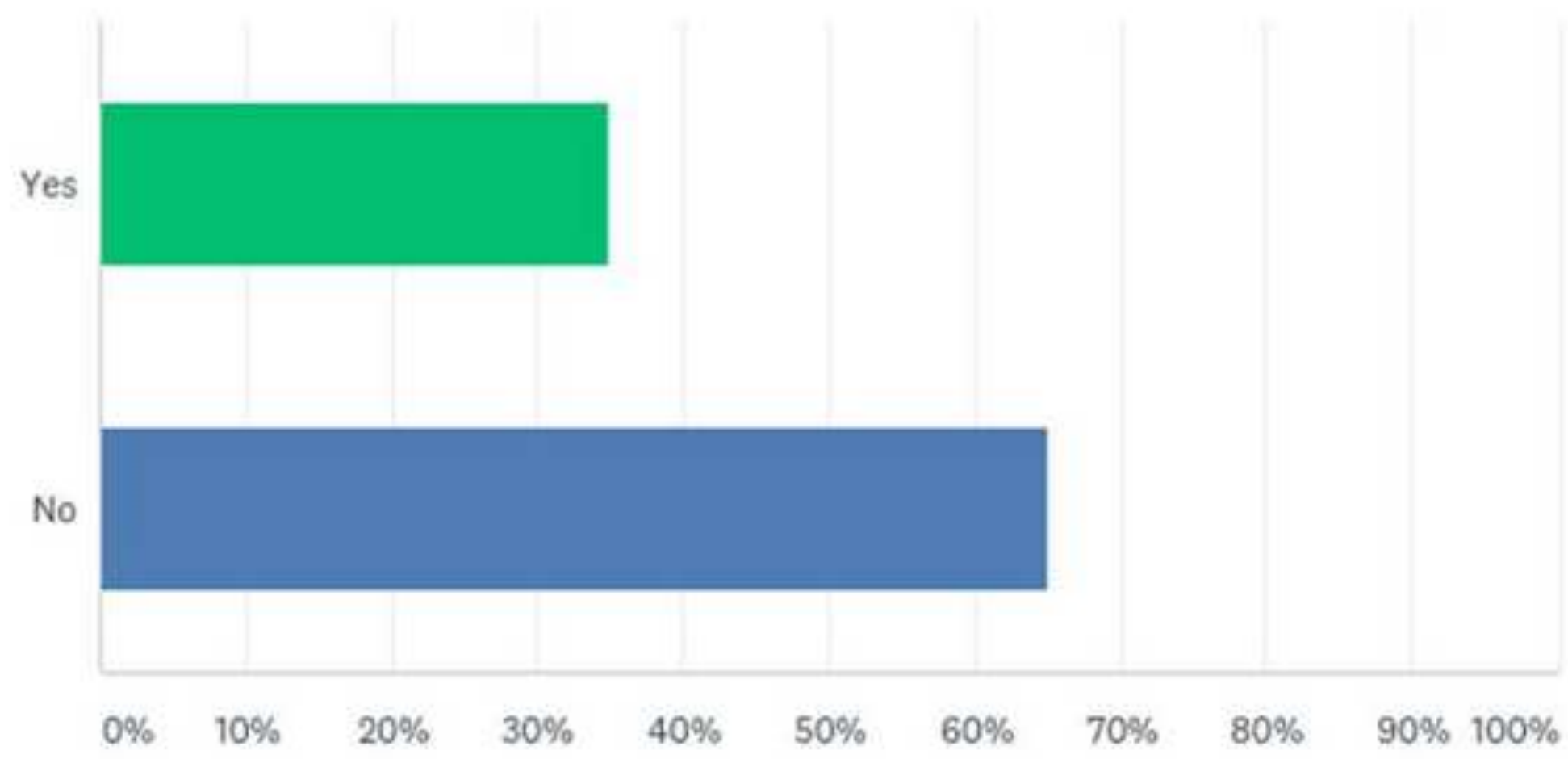


Figura (Figure) 5

Click here to download high resolution image

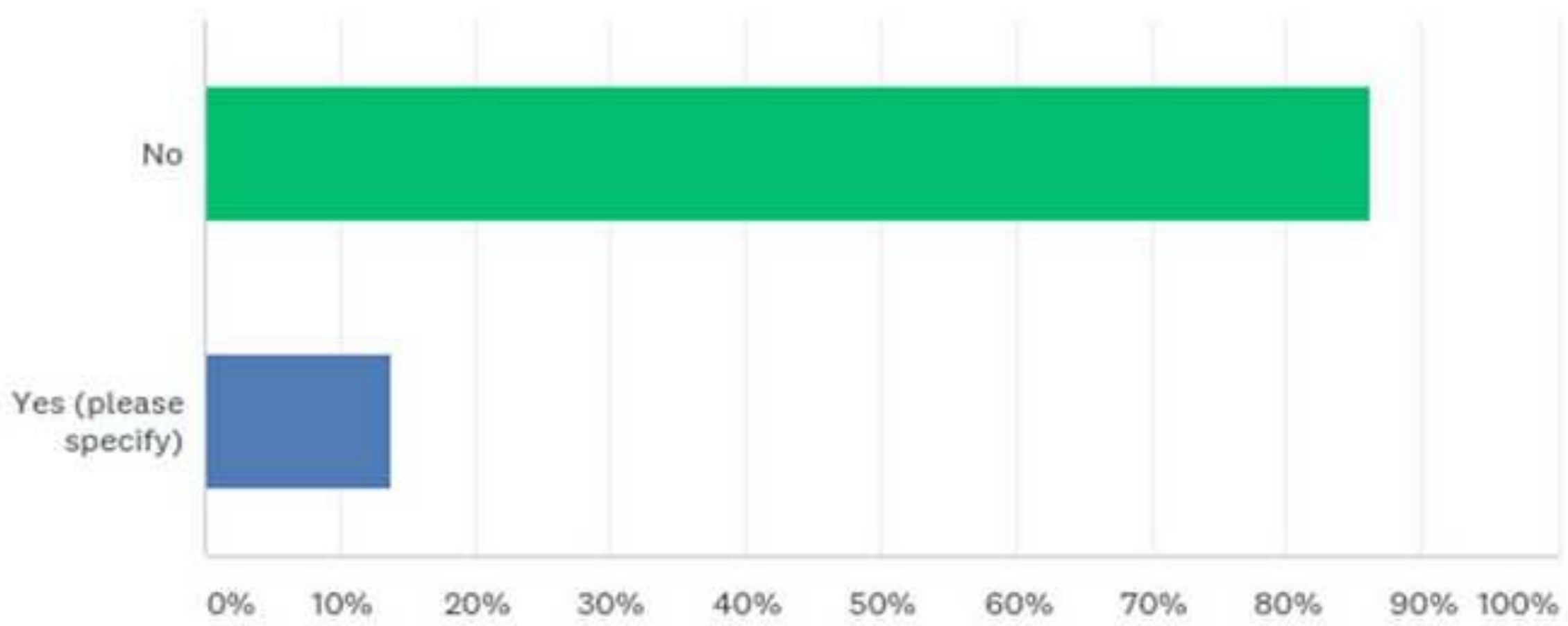

